\title{
Utilization of SSR Markers to Identify Slow Rusting Genes in Spring Wheat (Triticum aestivum L.)
}

\section{Ghassan Zahid ${ }^{1}$, Sania Begum ${ }^{2}$, Sikandar Almani ${ }^{3}$, Sahir Hameed Khattak ${ }^{2}$, Rajesh Kumar Soothar ${ }^{4}$ and Shakeel Ahmed Soomro**}

${ }^{1}$ Department of Biotechnology, The University of Azad Jammu and Kashmir, Muzaffarabad, 13100, Pakistan; ${ }^{2}$ Department of Plant Genomics and Biotechnology, National Agricultural Research Centre, Islamabad, 44000, Pakistan; ${ }^{3}$ Department of Chemical Engineering, Mehran University of Engineering and Technology, Jamshoro, 76060, Pakistan; ${ }^{4}$ Faculty of Agricultural Engineering, Sindh Agriculture University, Tandojam, 70060, Pakistan.

\begin{abstract}
The virulence of rust diseases in wheat crop like leaf, stripe and stem-rust declines the grain quality and productivity. Cultivars having a durable rust resistance is an effective method to control the spread of rust disease in cereal crops particularly in wheat. The experiment was conducted on fifty-two wheat lines comprised of forty-five double haploids of wheat along with seven wheat genotypes. Besides that, three positive checks and three SSR primers were also included in the study to check the durability i.e. Opata-85 Sr2/Lr27check, Pavon-76 ( $r r-29 / L r-46)$ and Tukuru (Yr18/Lr34) respectively. The molecular markers screening results indicated that the primer $S r 2 / L r 27$ was present in almost all of the double haploids and genotypes except the Nesser and Tukuru varieties. The Yr29/Lr46 gene complex was present in all double haploids and genotypes except for Nesser, Opata-85, inqilab-91 and Tukuru. the gene complex $\operatorname{rr} 18 / \operatorname{Lr} 34$ was present in eight double haploids, and only one genotype showed its presence, however the rest of the genotypes lacked this gene complex. The obtained results intimated that the 8 double haploids 33, 34, 44, $45,46,48,53,54$, and genotype weebil-1 contained all the slow rusting genes complex i.e. Yr18/Lr34, Yr29/ $\mathrm{Lr} 46$ and $\mathrm{Sr} 2 / \mathrm{Lr} 27$. Therefore, detection of slow rusting gene complex in these varieties with the assistance of molecular markers can be utilized for slow-rust resistance. Furthermore, the selected markers can be used as a primary choice for detecting rust resistance genes specifically in the wheat breeding population.

Received | May 17,2021; Accepted | November 17,2021; Published | February 16, 2022

*Correspondence | Shakeel Ahmed Soomro, Faculty of Agricultural Engineering, Sindh Agriculture University, Tandojam, 70060, Pakistan; Email: shakeelsoomro@live.com

Citation $\mid$ Zahid, G., S. Begum, S. Almani, S.H. Khattak, R.K. Soothar and S.A. Soomro. 2022. Utilization of SSR markers to identify slow rusting genes in spring wheat (Triticum aestivum L.). Pakistan Journal of Agricultural Research, 35(1): 85-92.

DOI | https://dx.doi.org/10.17582/journal.pjar/2022/35.1.85.92

Keywords | Wheat, Simple sequence repeats, Rust diseases, Molecular markers, Durable rust resistance
\end{abstract}

\section{Introduction}

W Theat (Triticum aestivum L.) is cultivated in diverse environments across the globe. It is consumed by $35 \%$ of the total world population as a staple food (IDRC, 2010), while overall it is consumed by more than 4.5 billion peoples providing $21 \%$ in terms of food calories, and more than $20 \%$ as protein (Soomro et al., 2017). Besides this, it is a highly profit- able crop for many small landholding farmers (Arzani and Ashraf, 2017). The cultivation of wheat crop is of great significance which provides an ample amount of food and nutrition to under-developed countries, and can be handful to overcome food insecurity and nutritional insecurity in the world (Grote et al., 2021) . Long et al. (2015) reported that by 2050, the annually demand for the wheat crop will rise at $1.6 \%$. Therefore, to meet this proliferate demand average yield of March 2022 | Volume 35 | Issue 1 | Page 85 
the wheat crop has to elevate from 3 tons (currently) to 5 tons per hectares. In Pakistan, Wheat is a key cereal crop that has a vital role to meet the food requirements, which is also ranked $8^{\text {th }}$ with the production of 24,348 tonnes (FAO, 2019) and 25,248 tonnes respectively (PBS, 2019-20). It occupies the vital place to formulate farming strategies adding 9.2 percent to the worth in the agriculture sector, and conctributing 1.8 percent to the GDP of Pakistan (PBS, 2019-20) . Climatic change and global warming have a direct impact on productivity, which can also greatly affect the world's agriculture sector (Memon et al., 2017). Due to the irregular fluctuations in the weather patterns, the world's significant cereal crop i.e. wheat is prone to different abiotic stresses i.e. drought, rise in temperatures and salinity, which are not suitable for cultivation (Chattha et al., 2018). These diseases keeps the plant under tremendous stress at all stages of its growth (Martínez et al., 2001).

Rust diseases are highly prolific whereas, they contain spores that tend to spread and travel long distances (Bhanbhro et al., 2019). They start to grow anywhere they find a proficient substrate (wheat species) under favorable conditions ( $\mathrm{Naz}$ et al., 2016). It is one of the fatal diseases and mainly responsible for the heavy losses in terms of productivity and quality of the grains, thus possess a serious threat to wheat production. Rust has been documented to be one of the oldest and significant diseases of wheat (Smith et al., 2002), posing a constant threat to all these sustainable wheat producing areas (Li et al., 2010). Due to this ability, they can cause a fast-paced epidemic with heavy losses, which makes it badly hampered by rusts than any other disease (Brown and Hovmø11, 2002). Periodic rust epidemics over the last century had created a famine scenario in the world (Manning et al., 2013) . It is estimated that more than $\$ 5$ billion is lost to cereal rusts worldwide each year (Chen et al., 2014). Leaf rust is an airborne disease (Wellings, 2011), and a well renowned domesticated disease of wheat across the globe (Huerta-Espino et al., 2011). Leaf rust prevalent in Pakistan as well due to its favorable temperatures prevailing throughout the season. Losses due to leaf rust vary for regions and years, and may cause losses varying between 15 to 60 percent (McIntosh and Yamazaki, 2008). Stem rust was first identified in Uganda in 1998 (Ug99), this race transfers its virulence from Uganda to various countries like Egypt, Iraq, Yemen and in Eastern parts of Africa (Singh et al., 2015). The virulence of black stem rust prevails in the entire country, but most of its epidemic form is seen in eastern and southern parts of Pakistan, where normally high temperature prevails during the crop season. Stripe rust or yellow rust is the air-borne disease of wheat (Huerta-Espino et al., 2011). Stripe rust prevails and loves to stay in cooler, humid and wetter climatic conditions of Europe and Asian territories particularly. However, literature reported that its prevalence is not only limited to certain regions moreover, its prevalence had been recorded across the globe (Wellings et al., 2012). Yellow rust or stripe rust is incredibly lethal and it has been reported that they decline the productivity of wheat from 5\% to 50\% (Yu et al., 2014). The mechanism of spreading leaf and stripe rust in wheat crop first starts from uredinia which appear first on the leaves. On the other hand, urediospores are the one which are produced from uredinia causing infection in the leaves of wheat (Chen et al., 2014). Nevertheless, the symptoms of both leaf and stripe rust are almost alike to each other and occur simultaneously as well (Wang et al., 2014). Breeding along with the pyramiding of resistance genes into cultivar is way ahead and had been proven successful than individuals having single race-specific genes (Spielmeyer et al., 2005). Ellis et al. (2014) reported that the combination of Lr34, Lr46 and $\mathrm{Sr} 2$ slow rusting genes is of great significance and categorized as backbone genes. They showed potent resistance when combined with other major genes or unknown minor genes i.e. QTLs. This phenomenon could be worth full in the wheat breeding improvement program. Marker assisted selection is an effective means for early selection of tricky characters hence, it is helpful in screening of difficult traits that cannot be identified easily by the traditional methods (Collard and Mackill, 2008). SSR makers proved to be handy for selection in plant genetics due to their imitate, multi-allelic character, co-dominant bequest and relative profusion, they further reported that about 52 leaf rust confrontation genes from wheat and wheat-related germplasm have been cataloged, obtaining their specific molecular markers (McIntosh and Yamazaki, 2008).

Keeping the importance of study in view and observing the losses in wheat due to rust, it makes it important to identify the resistant lines by various morphological and molecular techniques. To overwhelm this extensive diet needs, its cultivation and breeding are of great significance. This study was therefore carried out to detect slow rusting genes in wheat genotypes 
Table 1: Set of microsatellite markers used for the identification of slow rusting genes in wheat (Triticum aestivum L.).

$\begin{array}{llll}\begin{array}{l}\text { Gene } \\ \text { Lr34/Yr18 }\end{array} & \begin{array}{l}\text { Marker } \\ \text { GWM 295 }\end{array} & \begin{array}{l}\text { The sequence of primers (5'-3') } \\ \text { GTG AAG CAG ACC CAC AAC AC GAC } \\ \text { GGC TGC GAC GTA GAG }\end{array} & \begin{array}{l}\text { Reference } \\ \text { (Suenaga, Singh, Huerta-Espino, \& William, } \\ \text { 2003) }\end{array} \\ \text { Lr46/Yr29 } & \text { GWM 259 } & \begin{array}{l}\text { AGG GAA AAG ACA TCT TTT TTT TCCGA } \\ \text { CCG ACT TCG GGT TC }\end{array} & \begin{array}{l}\text { (M. William, Singh, Huerta-Espino, Ortiz } \\ \text { Islas, \& Hoisington, 2003) }\end{array} \\ \text { Sr2/Lr27 } & \text { STM559 } & \begin{array}{l}\text { AAGGCGAATCAAACGGAATATGTGTGT- } \\ \text { GTGTGTGAGAGAGAG }\end{array} & \text { (Hayden, Kuchel, \& Chalmers, 2004) }\end{array}$

using specific DNA-markers, and the validation of these DNA markers of slow rusting genes to assist future breeding programs.

\section{Materials and Methods}

The current study was conducted in the Laboratory of Plant Breeding and Molecular Genetics, University of Poonch, Azad Kashmir, Pakistan. Experimental material included 45 Double Haploids and 7 wheat genotypes including 3 positive checks for slow rusting genes. Experimental material were acquired from Wide Crosses Lab NARC Islamabad. Screening of double haploids for slow rusting genes (Yr18/Lr34, Yr29/Lr46 and Sr2/Lr27 gene complexes) was carried out using SSR markers.

\section{DNA extraction and molecular marker analysis}

DNA was isolated from seven-day-old seedlings (Figure 1) of 52 genotypes which were grown in the tray using an equal amount of sand, farmyard manure and clay at room temperature. Seedlings emerged after 1 week and they were further used for the isolation of DNA.

\section{DNA extraction protocol}

Fresh young leaves were grinded in $10 \mathrm{ml}$ of $2 \mathrm{XCTAB}$ solution and DNA was extracted by using the CTAB method protocol with some modifications (Doyle and Doyle, 1987). To digest RNA from the sample, two microliters of RNase was added to the DNA pellet at $37{ }^{\circ} \mathrm{C}$ for 1 hour.

\section{Quality of DNA}

Integrity and quality of DNA were tested in gel electrophoresis using $50 \mu \mathrm{g}$ DNA in $0.8 \%$ agarose gel. The samples identifying smear in the gels were discarded, where the DNA isolation was repeated.

\section{Quantification of $D N A$}

For quantification of 52 DNA, wheat samples were performed in an automated spectrophotometer that measured absorbance at $260 \mathrm{~nm}$.

\section{Different concentrations of $P C R$ reagents}

The Polymerase chain reaction was carried out in 2.0 $\mu 1$ of 10X PCR buffer, dNTPs $4.0 \mu 1$ of $2.5 \mathrm{mM}$ concentration, $\mathrm{MgCl} 21.6 \mu \mathrm{l}$ of $25 \mathrm{mM}$, forward and reverse primers $1.5 \mu \mathrm{l}$ of each, genomic DNA $2.0 \mu \mathrm{l}$ of each and double distilled water $7.15 \mu$, making a total volume of $20 \mu \mathrm{l}$ of each reaction. PCR was carried out in an Advanced BioRAD 25 PCR machine.

\section{Gel Electrophoresis}

The agarose gel was prepared using TBE buffer, which was then visualized under UV light by ethidium bromide staining. Gel documentation system (UV-tec made in the UK) was used for taking photographs. Amplified DNA fragments in PCR were electrophoresed on agarose gels (3.0 \%) using TBE buffer $(0.5 \mathrm{X})$.

\section{Results and Discussions}

Screening of wheat genotypes with primer GWM259 (Lr46/Yr29)

Forty-five double haploids along with seven wheat genotypes were screened for durable rust-resistant gene complex Lr46/Yr29 by using a specific primer for 46/Yr29 (Table 1). All Forty-five double haploids of wheat (1-5, 7-15, 17-22, 24-29, 32-36, 38, 40-42, 44-46, 48, 49, 51-56) along with three genotypes (Sitta, Weebil-1, Pavon-76) showed amplification, while genotype inqilab-91 and tukuru lacked this gene complex (Lr46/Yr29). By using a primer GWM259 (Lr46/Yr29) the check variety Pavon-76 showed amplification, while other two check varieties Nesser and Opata-85 lacked the gene complex i.e. Lr46/Yr29, where $\mathrm{C} 2$ indicates check 2 as shown in Figure 2.

Leaf rust resistant gene Lr46 is a durable resistant gene. These genes do not confer complete resistance to host plants against Puccinia triticina races. Apart from these they can post bond the septicity process or diminish the expansion of symptoms produced 
by a broad spectrum of leaf rust genotypes on adult plants. The results are in line with the findings of Singh (1992), whom first determined Lr46 that was in Pavon-76. Lr46 was accountable for proliferation in the segment of initially terminated fungal associations. Resistance granted by Lr46 is the same that is provided by Lr34. Lr46 was also found to be tightly linked with the durable rust resistance gene Yr29. This linkage of a slow rusting gene to a stem rust resistance gene was also reported for a pair Lr34/Yr18 (William et al., 2006) . Lr46 was transmitted from Pavon-76 to vulnerable genotypes like Jupateco 73 and Avoct. Also, substitution lines of Lalbahadur with chromosome 1B of Pavon-76 were established. One more novel basis for Lr46 was cultivar Parula.

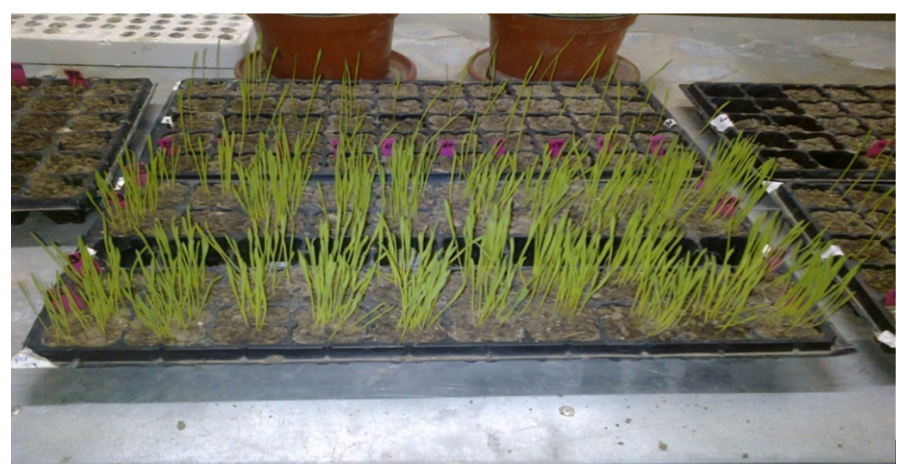

Figure 1: One week-old wheat experimental seedlings.

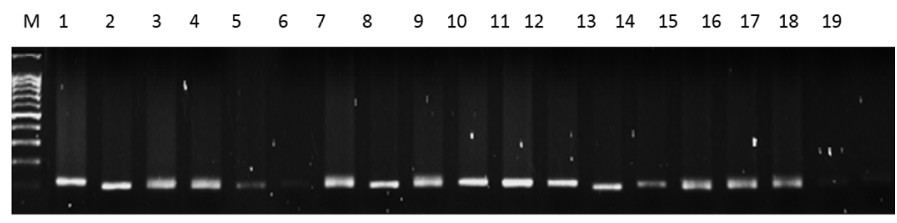

$\begin{array}{lllllllllllllllllllll}M & 20 & 21 & 22 & 23 & 24 & 25 & 26 & 27 & 28 & 29 & 30 & 31 & 32 & 33 & 34 & 35 & 36 & 37 & 38 & 39\end{array}$
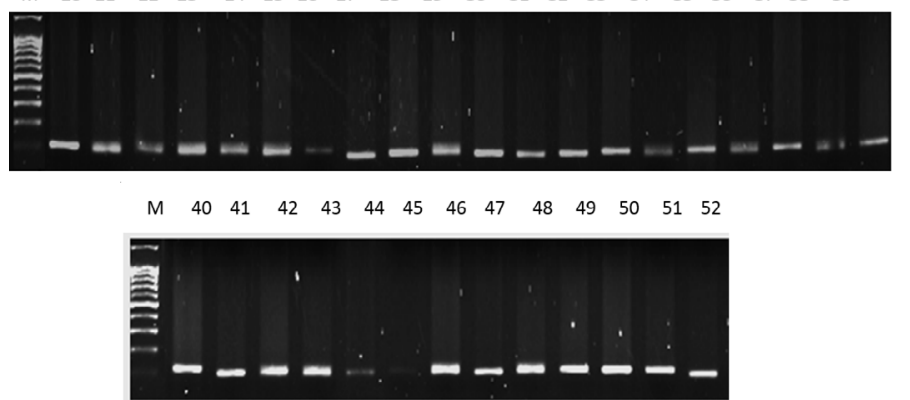

Figure 2: Amplification with primers GWM 259 (Lr-46+Yr-29) from genotype 1 to 52 .

Screening of wheat genotypes with Primer STM 559 (Sr2/Lr27)

Forty-five double haploids of wheat along with seven genotypes of wheat were screened with STM 559 primer for the presence of genes $\mathrm{Sr} 2 / \mathrm{Lr} 27$ along with check variety Opata-85. All forty five double haploids of wheat $(1,2,3,4,5,7,8,9,10,11,12,13,14,15,17$, $18,19,20,21,22,24,25,26,27,29,32,33,34,35$,
$36,38,40,41,42,44,45,46,48,49,51,52,53,54$, 55,56 ) along with five genotypes (Inqilab-91, Sitta, Weebil-1, Opata- 85, Pavon-76) showed amplification by using specific primer in PCR except negative checks Nesser and Tukuru, and Positive checks Opata-85 (C3), whereas C3 indicates check 3 showed amplification as shown in Figure 3.
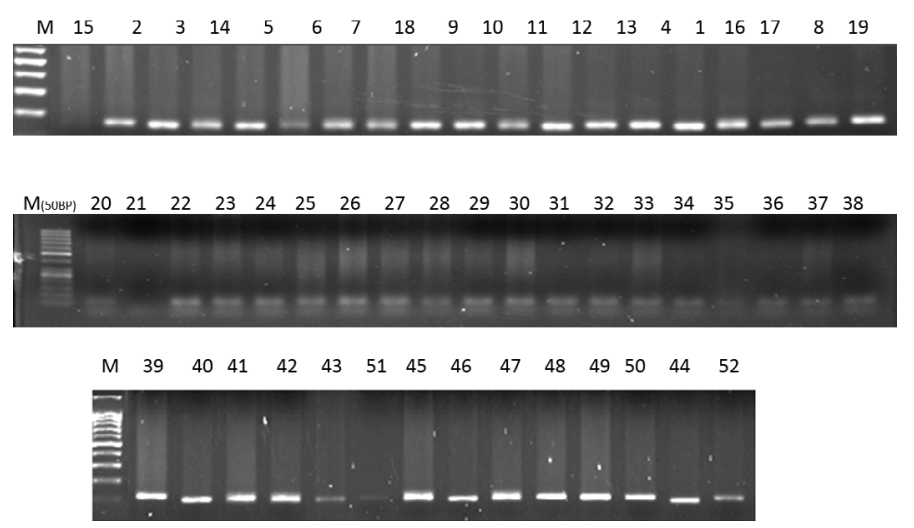

Figure 3: Amplification with primers STM 559 (Sr-2+Lr-27) from genotype 1 to 52 .

The manifestation of Sr2/ Lr27 in these genotypes of wheat is perhaps because of dispersal of semidwarf wheat varieties resistant to black rust from CIMMYT. A lofty incidence of Sr2/ Lr27 gene in wheat genotypes was also found. The gene provides a non-race-specific response and is linked to erratic signal levels of disease signs affected by genetic conditions and environmental background. Sr2/ Lr27 is one of the significant genes of black rust that confer adult plant immunity and is used in recent plant breeding (Mclntosh and Yamazaki, 2008). The recessive nature of heredity makes selection in breeding programs very complex (Mishra et al., 2005). The existence of this gene is linked with phonetic indicator pseudo-black chaff, a unique, spike and stem pigmentation in adult plants. Pseudo-black Chaff may help in the selection of $\mathrm{Sr} 2$ / Lr27 but it is not a reliable indication, as its expression depends on genetic background and environmental condition and its level is negatively linked to grain production. The Ug99 black rust disease epidemic is alarming because it signed the breakdown of black rust resistance that defend wheat cultivars. Many genotypes grant immunity to this pathotype $\mathrm{Sr} 2 / \mathrm{Lr} 27$ with other additive genes of similar nature that can be combined to create adult plant resistance. This pathotypic marker can be used in breeding for black rust which requires more concern. Hence marker-assisted selection breeding can be helpful to assist selection for these slow rusting genes. 
Table 2: Wheat genotypes with multiple slow rusting genes.

\section{S.No. Entry Name}

01 Double Haploid- 33

02 Double Haploid- 34

03 Double Haploid- 44

04 Double Haploid- 45

05 Double Haploid- 46

06 Double Haploid- 48

07 Double Haploid- 53

08 Double Haploid- 54

09 Weebill-1

\section{Slow Rusting Genes}

Lr34+Yr18, Lr46+Yr29, Sr2+Lr27

Lr34+Yr18, Lr46+Yr29, Sr2+Lr27

Lr34+Yr18, Lr46+Yr29, Sr2+Lr27

Lr34+Yr18, Lr46+Yr29, Sr2+Lr27

Lr34+Yr18, Lr46+Yr29, Sr2+Lr27

Lr34+Yr18, Lr46+Yr29, Sr2+Lr27

Lr34+Yr18, Lr46+Yr29, Sr2+Lr27

Lr34+Yr18, Lr46+Yr29, Sr2+Lr27

Lr34+Yr18, Lr46+Yr29, Sr2+Lr27
Parentage

CROC_1/AE.TAUSCHII(224)//OPATA

CROC_1/AE.TAUSCHII(224)//OPATA

PASTOR/BAV92

IRENA_BABAX//PASTOR

IRENA_BABAX//PASTOR

BJY/COC//PRL/BOW/3/ATTILA

VEEMJI//2*TUI/3/2* PASTOR

MILAN/KAUZ//BABAX/3/BABAX

Unknown

Screening of wheat genotypes with primer GWM295 (Lr34/Yr18)

Among forty-five double haploids along with seven genotypes of wheat, eight double haploids including (Double haploid-33, 34, 44, 45, 46, 48, 53, 54), and with one wheat genotype (Weebil-1) showed amplification by using a specific primer in PCR except for negative checks Pavon-76 and Nesser, and positive checks Tukuru (C1), whereas $\mathrm{C} 1$ indicates check 1 yielded the PCR product with primer GWS 295 for Lr34/Yr18 as shown in Figure 4. Genotypes name and their presence or absence (+/-) shows that these cultivars carry leaf rust and stripe rust resistance genes complex (Lr34/Yr18). Forty-one cultivars fail to amplify any PCR product using GWM 295 primer. Similar results using Pakistani wheat cultivars demonstrated that these cultivars carry leaf rust resistance genes (Aktar-Uz-Zaman et al., 2017).
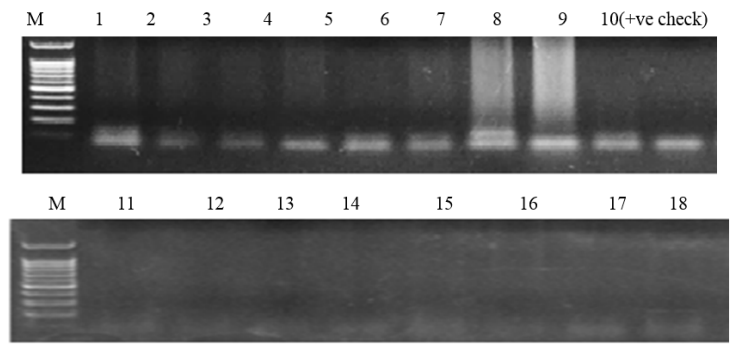

M $\quad \begin{array}{lllllllllllllllllll}19 & 21 & 22 & 20 & 23 & 24 & 25 & 26 & 37 & 28 & 29 & 30 & 31 & 32 & 33 & 34 & 35 & 36 & 27\end{array}$

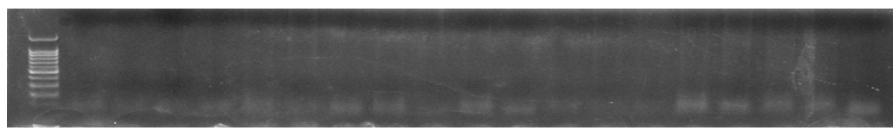

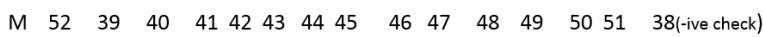

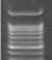

Figure 4: Amplification with primers GWM 295 (Lr 34/ $\mathrm{Yr} 18)$ from genotype 1 to 52

Lr34 and stripe rust resistance gene Yr18 showed less frequency of presence in wheat cultivars. The stumpy occurrence of $\mathrm{Lr} 34 / \mathrm{Yr} 18$ showed that the concerned gene cluster has not been integrated into double hap- loid and other genotypes used in the present study by wheat breeders. The use of this durable resistance gene complex (Lr34/ Yr18) with other minor genes for resistance gives close protection to leaf and stripe rust infection (Duveiller et al., 2007). Leaf rust resistance gene Lr34 has been initiated still granting resistance to leaf rust. Therefore, this gene complex offers sufficient immunity against leaf and stripe rust in double haploids. The most famous and widely cultivated wheat variety of Pakistan "Inqilab-91" lacks Yr 18 gene. This variety is prone to stripe rust because of the collapse of the immunity of the Yr 27 gene (Smith et al., 2007). By adopting conventional or non-conventional breeding approaches this gene can be incorporated into Inqilab-91 from these durable haploids to lessen the occurrence of stripe rust in Pakistan. Marker Assisted Selection is a useful tool to transfer these genes into adapted wheat varieties. Leaf tip necrosis is also firmly associated with the presence of the Lr 34 gene. However, selection based on Ltn can occasionally be deceptive.

Wheat genotypes with multiple slow rusting genes are presented in Table 2. Nine genotypes showed all the three slow rusting gene complexes (Yr18/Lr34, Yr29/ Lr46 and Sr2/Lr27) included in the study. These gene complexes can be maintained in segregating populations by selecting for leaf tip necrosis or pseudo-black chaff phenotypes. Because the leaf tip necrosis is associated with the durable rust resistance gene Lr34 / Yr18 and the pseudo black Chaff is associated with Sr2.

\section{Conclusions and Recommendations}

The present study employed SSR markers for detecting rust resistance genes in the developed population March 2022 | Volume 35 | Issue 1 | Page 89 
of spring wheat. It was observed that the primer $\mathrm{Sr} 2 /$ Lr27 was present in almost all the genotypes except the negative checks Nesser and Tukuru. The Yr29/ Lr46 gene complex showed presence, but in the varieties Nesser, Opata-85, inqilab-91 and Tukuru it was absent for the gene $\operatorname{Yr18} / \mathrm{Lr} 34$. Double haploid-33, 34, $44,45,46,48,53,54$, and genotype Weebil-1 showed its presence but the rest of the genotypes lacked this gene. In this study, it was concluded that the double haploid-33, 34, 44, 45, 46, 48, 53, 54 and genotype Weebil-1 contained all the slow rusting genes i.e. Yr18/Lr34, Yr29/Lr46 and Sr2/Lr27. Breeders may use these genotypes having slow rusting genes in their breeding programs to exploit potential yield. Along with, it is significant to diagnose the virulence of rust disease accurately by the use of transgenic, genome editing and growing rust-resistant cultivars to attain endurable and durable rust resistance against various wheat crop diseases.

\section{Novelty Statement}

The novelty of this work exhibits a wide range of local spring wheat samples comprising double haploids and genotypes. After molecular characterization and screening, it was possible to identify the durable rust-resistant genes that could be highly beneficial to combat the virulence of wheat rust disease. Besides this, it also ensures food security in highly populated countries like Pakistan which ultimately maximize the genetic resources available to mitigate the wheat rusts.

\section{Author's Contribution}

Ghassan Zahid: Conceived the idea and conducted the experiment.

Sania Begum: Provided technical input and helped in developing the methodology section. Sahir Hameed Khattak: Analysed the data.

Ghassan Zahid and Shakeel Ahmed Soomro: Wrote the manuscript.

Sikandar Almani and Rajesh Kumar Soothar: Reviewed and provided input in final manuscript.

\section{Supplementary material}

There is supplementary material associated with this article. Access the material online at: https://dx.doi. org/10.17582/journal.pjar/2022/35.1.85.92
Conflict of Interest

The authors have declared no conflict of interest.

\section{References}

Aktar-Uz-Zaman, M., Tuhina-Khatun, M., Hanafi, M.M. and Sahebi, M. 2017. Genetic analysis of rust resistance genes in global wheat cultivars: an overview. Biotechnol. Biotechnol. Equip., 31(3): 431-445. https://doi.org/10.108 0/13102818.2017.1304180

Arzani, A. and M.Ashraf. 2017. Cultivated Ancient Wheats (Triticum spp.): A Potential Source of Health-Beneficial Food Products. Compr. Rev. Food Sci. Food Saf., 16(3): 477-488. https:// doi.org/10.1111/1541-4337.12262

Bhanbhro, L.B., H.B. Bozdar, S.A. Soomro, M.A. Jatoi, A.A. Bughio, M. Faheem, M. Arshad, A.A. Rajper and A.A. Mirani. 2019. Agronomic performance of some alien bread wheat (Triticum aestivum) lines under agroecological conditions of Sakrand, Pakistan. Pure Appl. Biol., 8(4): 2135-2142. https://doi. org/10.19045/bspab.2019.80158

Brown, J.K.M. and M.S. Hovmøll. 2002. Aerial dispersal of pathogens on the global and continental scales and its impact on plant disease. Science, 297(5581): 537-541. https:// doi.org/10.1126/science.1072678

Chattha, S.H., B.N. Mirani, S.A. Soomro, K.A. Ibupoto, H.R. Mangio, G.M. Khush, A.A. Abro, Z.A. Khan and L. Zhao. 2018. Comparative study of different storage methods for postharvest preservation of wheat grain. Sci. Technol. Dev., 37(1): 1-5.

Chen, W., C. Wellings, X. Chen, Z. Kang and T. Liu. 2014. Wheat stripe (yellow) rust caused by Puccinia striiformis f. sp. tritici. Mol. Plant Pathol., 15(5): 433-446. https://doi. org/10.1111/mpp.12116

Collard, B.C.Y. and D.J. Mackill. 2008. Markerassisted selection: An approach for precision plant breeding in the twenty-first century. Philos. Trans. R. Soc. B. Biol. Sci., 363(1491): 557-572. https://doi.org/10.1098/rstb.2007.2170

Doyle, J. and J. Doyle. 1987. A rapid isolation procedure for small amounts of leaf tissue. Phytochem. Bull., 19(1): 11-15.

Duveiller, E., R.P. Singh and J.M. Nicol. 2007. The challenges of maintaining wheat productivity: Pests, diseases, and potential epidemics. 
Euphytica, 156: 417-430. https://doi. org/10.1007/s10681-007-9380-z

Ellis, J.G., E.S. Lagudah, W. Spielmeyer and P.N. Dodds. 2014. The past, Present and future of breeding rust resistant wheat. Front.Plant Sci.,5: 1-13. https://doi.org/10.3389/fpls.2014.00641

FAO, 2019. Food and Agriculture Organization of the United Nations - Statistics Division, http:// www.fao.org/faostat/en/\#data/QC (accessed 28.04.2020), FAOSTAT.

Grote, U., A. Fasse, T.T. Nguyen and O. Erenstein. 2021. Food Security and the Dynamics of Wheat and Maize Value Chains in Africa and Asia. Front. Sustain. Food Syst., 4: 617009:2-17. https://doi.org/10.3389/fsufs.2020.617009

Huerta-Espino, J., R.P. Singh, S. Germán, B.D. McCallum, R.F. Park, W.Q. Chen, S.C. Bhardwaj and H. Goyeau. 2011. Global status of wheat leaf rust caused by Puccinia triticina. Euphytica, 179: 143-160. https://doi. org/10.1007/s10681-011-0361-x

IDRC. 2010. Facts and Figures on Food and Biodiversity. Canada: IDRC Communications, International Development Research Centre. Availble online at: https://www.idrc.ca/en/ research-in-action/facts-figures-food-andbiodiversity

Li, Z.F., X.V. Xia, Z.H. He, X. Li, L.J. Zhang, H.Y. Wang, Q.F. Meng, W.X. Yang, G.Q. Li, and D.Q. Liu. 2010. Seedling and slow rusting resistance to leaf rust in Chinese wheat cultivars. Plant Dis., 94(1): 45-53. https://doi. org/10.1094/PDIS-94-1-0045

Long, S.P., A. Marshall-Colon and X.G. Zhu. 2015. Meeting the global food demand of the future by engineering crop photosynthesis and yield potential. Cell, 161(1): 56-66. https://doi. org/10.1016/j.cell.2015.03.019

Manning, V.A., I. Pandelova, B. Dhillon, L.J. Wilhelm, S.B. Goodwin, A.M. Berlin, M.Figueroa,M.Freitag,J.K.Hane, B.Henrissat, W.H. Holman, C.D. Kodira, J. Martin, R.P. Oliver, B. Robbertse, W. Schackwitz, D.C. Schwartz, J.W. Spatafora, B.G. Turgeon, C. Yandava, S. Young, S. Zhou, Q. Zeng, V.G. Igor, L.G. Ma and L.M. Ciuffetti. 2013. Comparative genomics of a plant-pathogenic fungus, pyrenophora tritici-repentis, reveals transduplication and the impact of repeat elements on pathogenicity and population divergence. G3 Genes, Genomes, Genet., 3(1):
41-63.

Martínez, F., R.E. Niks, R.P. Singh and D. Rubiales. 2001. Characterization of Lr46, a gene conferring partial resistance to wheat leaf rust. Hereditas, 135(2-3): 111-114. https://doi. org/10.1111/j.1601-5223.2001.00111.x

McIntosh, R. and Y. Yamazaki. 2008. Catalogue of gene symbols for wheat. Int. Wheat Genet. Symp.,

Memon, M.S., A.A. Tagar, J. Chunxia, J. Sijie, S.A. Soomro, P.K. Korai, N. Memon, M. Ameen and J. Changying. 2017. Influence of straw incorporation and tillage practices on sustainable wheat (Triticum aestivum L.) yield and soil organic carbon dynamics in rice-wheat rotation system. Int. Agric. Eng. J., 26(4): 8595.

Mishra, A.N., K. Kaushal, S.R. Yadav, G.S. Shirsekar and H.N. Pandey. 2005. The linkage between the stem rust resistance gene $\mathrm{Sr} 2$ and pseudo-black chaff in wheat can be broken. Plant Breed., 124(5): 520-522. https://doi. org/10.1111/j.1439-0523.2005.01136.x

Naz, M., F. Nizamani, G.S. Nizamani, M.R. Nizamani, S. Ahmed, N. Ahmed, S. Rehman and S.A. Soomro. 2016. Callus induction and plant regeneration from immature embryos of spring wheat varieties (Triticum aestivum L.) under different concentrations of growth regulators through tissue culture technique. Pure Appl. Biol., 5(3): 378-385. https://doi. org/10.19045/bspab.2016.50049

Pakistan Bureau of Statistics. 2019-20. Pakistan Statistical Year Book.

Singh, R.P. 1992. Genetic Association of Leaf Rust Resistance Gene Lr34 with Adult Plant Resistance to Stripe Rust in Bread Wheat. Phytopathology, 8(8): 835-838. https://doi. org/10.1094/Phyto-82-835

Singh, R.P., D.P. Hodson, Y. Jin, E.S. Lagudah, M.A. Ayliffe, S. Bhavani, M.N. Rouse, Z.A. Pretorius, L.J. Szabo, J. Huerta-Espino, B.R. Basnet, C. Lan and M.S. Hovmøller. 2015. Emergence and spread of new races of wheat stem rust fungus: Continued threat to food security and prospects of genetic control. Phytopathology, 105(7): 872-884. https://doi. org/10.1094/PHYTO-01-15-0030-FI

Smith, P.H., J. Hadfield, N.J. Hart, R.M.D. Koebner and L.A. Boyd. 2007. STS markers for the wheat yellow rust resistance gene $\operatorname{Yr} 5$ 
suggest a NBS-LRR-type resistance gene cluster. Genome, 50(3): 259-265. https://doi. org/10.1139/G07-004

Smith,P.H., R.M.D. Koebner and L.A. Boyd.2002. The development of a STS marker linked to a yellow rust resistance derived from the wheat cultivar Moro. Theor. Appl. Genet., 104(8): 1278-1282. https://doi.org/10.1007/s00122002-0895-3

Soomro, A., M. Nauman, S.A. Soomro, A.A.Tagar, S.A. Soomro, M. Buriro, A.W. Gandahi and A.H. Memon. 2017. Evaluation of raisedbed and conventional irrigation systems for yield and water productivity of wheat crop. J. Basic Appl. Sci., 13: 143-149. https://doi. org/10.6000/1927-5129.2017.13.24

Spielmeyer, W., R.A. McIntosh, J. Kolmer and E.S. Lagudah. 2005. Powdery mildew resistance and Lr34/Yr18 genes for durable resistance to leaf and stripe rust cosegregate at a locus on the short arm of chromosome 7D of wheat. Theor. Appl. Genet., 111(44): 731-735. https://doi. org/10.1007/s00122-005-2058-9

Wang, X., Z. Ma, Y. Jiang, S. Shi, W. Liu, J. Zeng, Z. Zhao and H. Wang. 2014. Modeling of the overwintering distribution of Puccinia striiformis f. sp. tritici based on meteorological data from 2001 to 2012 in China. Front. Agric. Sci. Eng., 1(3): 223-235. https://doi. org/10.15302/J-FASE-2014025

Wellings, C.R. 2011. Global status of stripe rust: A review of historical and current threats. Euphytica, 179(1): 129-141. https://doi. org/10.1007/s10681-011-0360-y

Wellings, C.R., L.A. Boyd and X.M. Chen. 2012. Resistance to stripe rust in wheat: Pathogen biology driving resistance breeding. Dis. Resist. Wheat, 4: 335-342. https://doi. org/10.1079/9781845938185.0063

William, H.M., R.P. Singh, J. Huerta-Espino, G. Palacios and K. Suenaga.2006. Characterization of genetic loci conferring adult plant resistance to leaf rust and stripe rust in spring wheat. Genome, 49(8): 977-990. https://doi. org/10.1139/g06-052

Yu, L.X., H. Barbier, M.N. Rouse, S. Singh, R.P. Singh, S. Bhavani, J. Huerta-Espino and M.E. Sorrells. 2014. A consensus map for Ug99 stem rust resistance loci in wheat. Theor. Appl. Genet., 127(7): 1561-1581. https://doi.org/10.1007/ s00122-014-2326-7 